\title{
The diagnostic performance of three-dimensional contrast-enhanced magnetic resonance angiography in demonstrating renal vasculature in patients with suspected renovascular hypertension
}

\section{Renovasküler hipertansiyon şüphesi olan hastalarda renal arterlerin görüntülenmesinde üç boyutlu kontrastlı manyetik rezonans anjiyografinin tanı değeri}

\author{
Meltem Özdemir ${ }^{1 *} \mathbb{D}$, Tahsin Rendan Edgüer ${ }^{1}$, Halil Öztürk ${ }^{1}$, Emine Öztürk ${ }^{1}$, Alper Dilli ${ }^{1}$ (D), \\ Baki Hekimoğlu ${ }^{1}$ \\ ${ }^{1}$ University oh Health Science, Dışkapı Yıldırım Beyazıt Training and Research Hospital, Department of Radiology, Ankara, Turkey \\ * Corresponding author: Meltem Özdemir E-mail: meltemgu@yahoo.com ORCID: 0000-0002-7388-2871 \\ **This study was presented as a poster on October 26-31, 2001 at the 22nd Turkish Radiology Congress (TürkRad 2001, Antalya). \\ Received: 18 May 2018 Accepted: 14 July 2018
}

\begin{abstract}
Aim: The aim of our study was to evaluate the diagnostic value of three-dimensional contrast-enhanced magnetic resonance angiography (3D CE-MRA) in detecting renal artery stenosis (RAS), and in demonstrating segmental and accessory renal arteries in patients with suspected renovascular hypertension, taking digital subtraction angiography (DSA) as the reference method.
\end{abstract}

Material and Method: Twenty five patients underwent 3D CE-MRA and DSA. Sensitivity, specificity, positive predictive value, and negative predictive value of CE-MRA in depicting RAS, and sensitivity of the technique in demonstrating segmental and accessory arteries were calculated.

Results: For detecting RAS, the sensitivity, specificity, positive predictive value, and negative predictive value of 3D CE-MRA were; $100 \%, 97.8 \%, 87.5 \%$, and $100 \%$, respectively. The sencitivity of the technique in demonstrating segmental and accessory arteries were $58 \%$ and $91.7 \%$, respectively.

Conclusion: We found that 3D CE-MRA is a reliable technique in not only detecting RAS, but in demonstrating accessory arteries as well. However, according to our results, the value of the method in visualising segmental arteries is limited.

Keywords: renal MRA, magnetic resonance angiography, contrast-enhanced MRA

() 2019 by the authors; licensee MEDITAGEM Ltd., Turkey. This article is an open access article distributed under the terms and conditions of the Creative Commons Attribution License (http://creativecommons.org/licenses/by/4.0/). 


\section{ÖZ}

Amaç: Çalışmamızın amacı, digital subtraction angiography (DSA) tekniğini referans metod alarak, üç boyutlu kontrastlı manyetik rezonans anjiyografi (3D CE-MRA) tekniğinin, renal arter stenozu (RAS) tanısındaki ve segmental ve aksesuar renal arter görüntülemesindeki değerini saptamak idi.

Gereç ve Yöntem: Yirmi beş hastaya 3D CE-MRA ve DSA tetkikleri uygulandı. CE-MRA tekniğinin RAS tanısındaki sensitivite, spesifisite ve pozitif ve negatif kestirim değerleri ile tekniğin segmental ve aksesuar renal arter görüntülemedeki sensitivite değerleri hesaplandı.

Bulgular: RAS tanısında CE-MRA tekniğinin sensitivite, spesifisite, pozitif ve negatif kestirim değerleri, aynı sıra ile; \%100, $\% 97,8, \% 87,5$, ve \%100 olarak hesaplandı. Tekniğin segmental ve aksesuar renal arter görüntülemedeki sensitivite değerlerinin, aynı sıra ile; \%58 ve \%91,7 olduğu saptandı.

Sonuç: 3D CE-MRA tekniğinin, sadece renal arter stenozu tanısında değil, aksesuar arterlerin görüntülemesinde de güvenilir olduğu saptandı. Ancak çalışmamızın sonuçlarına göre, tekniğin segmental arter görüntülemesindeki değeri sınırlıdır.

Anahtar kelimeler: renal MRA, manyetik rezonans anjiyografi, kontrastlı MRA

\section{INTRODUCTION}

Renovascular hypertension is defined as the elevation of blood pressure as a result of renal artery stenosis (RAS) and activation of renin-angiotensin system. It constitutes the cause of $5.8 \%$ of all cases of secondary hypertension, and 1$2 \%$ of all cases of hypertension in general population [1]. Early diagnosis of renovascular hypertension plays a critical role in preventing the development of ischemic nephropathy and cardiovascular complications [2]. It is many experts' opinion that, radiologic evaluation of patients with suspected renovascular hypertension should be started with Doppler ultrasonography (DUS). It is a noninvasive diagnostic method for not only anatomical but functional evaluation of the renal arteries as well. In addition, DUS can be used to select candidates for successful revascularization and follow-up of renal arteries after revascularization [3-4]. Computed tomographic angiography (CTA) and magnetic resonance angiography (MRA) offer extensive demonstration of the aorta and renal arteries, often allowing depiction of multiple vessels, assessment of renal size, and anatomy [1]. Digital subtraction angiography (DSA) is the gold standard in the diagnosis of RAS. And it also provides the opportunity for the treatment of RAS by percutaneous angioplasty (with or without stenting) [5].

Contrast enhanced MRA (CE-MRA) is an efficient imaging method answering most clinical questions concerning the renal vasculature [2]. It demonstrates not only the lumen of the vessel as in DSA, but the vessel wall, renal parenchyma, collecting system, and neighboring soft tissue structures as well [6]. Sensitivities and specificities for CE-MRA in the assessment of RAS are reported to be upward of $90 \%$ [2]. The aim of our study was, to assess the diagnostic value of three dimensional (3D) CE-MRA in detecting RAS, and in demonstrating main, segmental, and accessory renal arteries taking DSA as the reference method.

\section{MATERIAL AND METHOD}

\section{Patient Selection and Study Design}

Between October 2000 and March 2001, with institutional review board approval, 25 patients underwent MRA and DSA. Informed consent was obtained from all patients. There were 15 men and 10 women with a mean age of 47.5 years (range: 15-70). The mean systolic/diastolic blood pressure values were 166/102 $\mathrm{mmHg}$ (range: 100/60- 260/160 $\mathrm{mmHg}$ ). Mean creatinine level was $1 \mathrm{mg} / \mathrm{dL}$ (range: 0.6-1.9 $\mathrm{mg} / \mathrm{dL}$ ). Mean glomerular filtration rate (GFR) was 58 $\mathrm{mL} / \mathrm{min} / 1.73 \mathrm{~m}^{2}$ (range: $28-103 \mathrm{~mL} / \mathrm{min} / 1.73 \mathrm{~m}^{2}$ ). Nineteen patients who were affected by hypertension and were suspected of having RAS were included in the study. Three patients who underwent percutaneous transluminal angioplasty (PTRA) were also enrolled; 2 of them underwent MRA following PTRA, and the third subject underwent MRA both prior to and following PTRA. In addition, 1 potential renal donor and 2 normotensive patients who underwent abdominal MRA for an indication other than RAS survey were also included in our study.

MRA and DSA examinations were performed within 10 days following refferal. Time elapsed between MRA and DSA was not over 7 days in any patient. 


\section{MRA Technique}

All examinations were performed with a $1.5 \mathrm{~T}$ superconductive scanner (Magnetom Vision/Vision Plus; Siemens) using a phased array body coil.

Initially, in order to visualize abdominal aorta and the origin of the renal arteries, a T1 weighted, multiplanar, fast spoiled gradient echo (FSPGR) sequence was performed with the following parameters: TR/TE, 15/6 ms; flip angle (FA), 30 ; number of slice, 5; slice thickness, $10 \mathrm{~mm}$; matrix, $128 \times 256$; field of view (FOV), $450 \mathrm{~mm}$; number of acquisition (NA), 1; acquisition time, $16 \mathrm{sec}$. The acquisition volume was positioned keeping the origin of the renal arteries in its center, comprising the region between proximal abdominal aorta and the femoral bifurcation.

In order to evaluate parenchymal and calyceal structures, fast imaging with steady state precession (FISP) sequence in both coronal and axial planes were performed using the following parameters: TR/TE, 4.8/2.3 ms; FA, 70 ; number of slice, 6; slice thickness, 6mm; matrix, 256x256; FOV, 350 mm; NA, 1; acquisition time, $14 \mathrm{sec}$. Craniocaudal dimensions of all kidneys were measured. Parenchyma thicknesses were measured in the upper, middle and lower zones of each kidney, and the mean value of three measures were taken as the final renal parenchymal thickness.

CE-MRA sequence was a breath-hold, 3D, FSPGR sequence, with the parameters as follows: TR/TE, 4.6/1.8 ms; FA, 30; slab thickness, 96; partition number, 32 ; slice thickness $3 \mathrm{~mm}$ (effective thickness, $1.5 \mathrm{~mm}$ ); matrix, 200x512; FOV, 390 mm; NA, 1; acquisition time, $23 \mathrm{sec}$. A coronal slab was centralized on abdominal aorta, and positioned as to include main branches and abdominal bifurcation. Suspension of respiration was required for the duration of $M R$ data acquisition. A $20 \mathrm{~mL}$ of gadopentate dimeglumine (Magnevist, $0.5 \mathrm{mmol} / \mathrm{L}$; Shering) was injected manually with an infusion velocity of $2 \mathrm{~mL} / \mathrm{s}$, followed by the administration of $40 \mathrm{~mL}$ of saline solution at the same speed. Pre-contrast images were subtracted from post-contrast images in order to obtain angiographic images.

CE-MRA images were reconstructed with a MIP algorithm with $360^{\circ}$ rotations of coronal axial planes. One projection per $30^{\circ}$ was obtained: finally, 12 longitudinal-oblique and 12 transverse-oblique angiograms were obtained. All native images and MIP projections were examined.

\section{DSA Technique}

Angiograms were obtained in digital subtraction angiography unit (Angiostar/Siemens). By a transfemoral approach, a $5 \mathrm{~F}$ pigtail catheter was placed in abdominal aorta as its side holes were prone to the origins of renal arteries. Following the intraarterial injection of $20 \mathrm{~mL}$ lohexol (Omnipaque $350 \mathrm{mg} \mathrm{I} / \mathrm{mL}$; Nycomed), renal angiograms were obtained. If needed, selective catheterization of renal artery was performed.

\section{Image Analysis}

MRA and DSA images were independently interpreted by two radiologists who were unaware of clinical findings. All DSA and MRA images were evaluated for the presence of stenosis and visibility of segmental and accessory arteries. Grade of the stenosis was defined as follows; normal renal artery, grade 0; $1-49 \%$ narrowing, grade 1; 50-74\% narrowing, grade 2; 75-99\% narrowing, grade 3; occlusion, grade 4 . Signal loss in a renal artery segment not longer than $1.5 \mathrm{~cm}$, and visibility of the normal lumen distal to the segment with signal loss was defined as grade 3 stenosis. Stenosis with narrowing more than $50 \%$ was defined to be hemodynamically significant.

In the evaluation of the visibility of main and segmental arteries; ostium and the segment within $1.5 \mathrm{~cm}$ to ostium was defined as proximal renal artery, and the segment 15-35 $\mathrm{mm}$ to ostium was defined as distal renal artery. The patients of whom only the proximal renal artery was visible were included in group 1; visible proximal and distal renal arterial segments were included in group 2; and visible proximal, distal and segmental arterial segments were included in group 3.

An accessory artery was defined as; extrahilar artery originating from aorta, extrahilar artery originating from main renal artery, or multiple hilar arteries.

\section{Statistical Analysis}

Results of CE-MRA were compared with those of DSA. The diagnostic indices including sensitivity, specificity, positive predictive value, and negative predictive value of CE-MRA in diagnosing RAS, and sensitivity of the technique in demonstrating accessory and segmental arteries were calculated using SPSS v.9 software (SPSS Inc., Chicago, IL, USA).

\section{RESULTS}

There has been no allergic reactions or complications in any patient during or following DSA and MRA acquisitions. All images obtained by CE-MRA were optimum in quality. 
Table 1. Comparative results of digital subtraction angiography and three dimensional contrast enhanced magnetic resonance angiography, in grading stenosis

\begin{tabular}{|c|c|c|c|c|}
\hline \multirow{2}{*}{ DSA } & \multicolumn{5}{|c|}{ CE-MRA } \\
\cline { 2 - 5 } & Grade 0 & Grade 1 & Grade 2 & Grade 3 \\
\hline Grade 0 & 46 & 0 & 1 & 0 \\
\hline Grade 1 & 3 & 5 & 1 & 0 \\
\hline Grade 2 & 0 & 0 & 0 & 5 \\
\hline Grade 3 & 0 & 0 & 0 & \\
\hline
\end{tabular}

DSA: Digital subtraction angiography, CE-MRA: Contrast enhanced magnetic resonance angiography
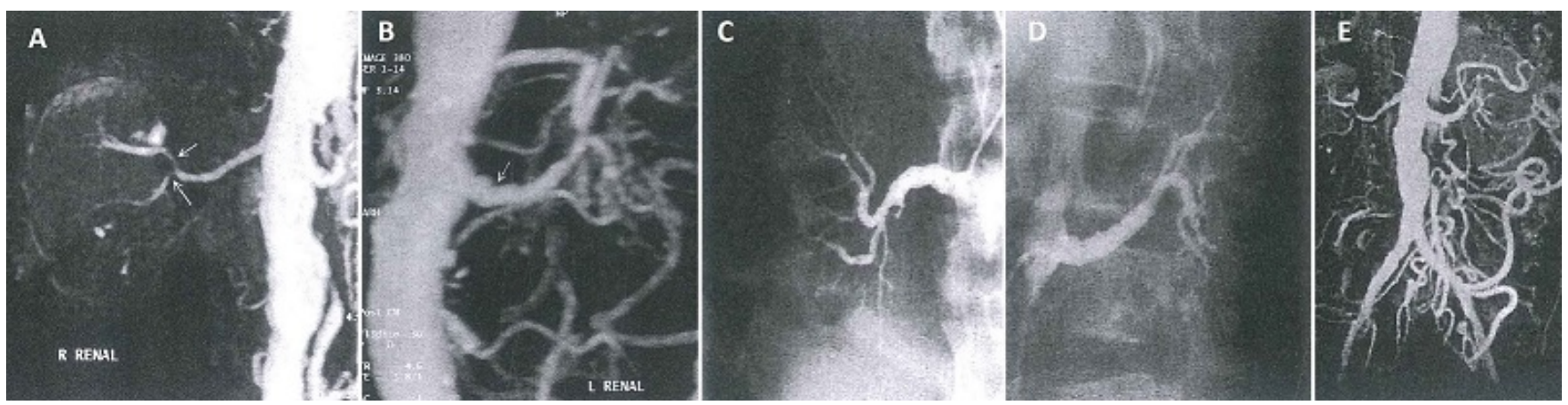

Figure 1. a) CE-MRA of right renal artery b) CE-MRA of left renal artery c) DSA of right renal artery d) DSA of left renal artery e) CE-MRA of abdominal aorta and its main branches. CE-MRA and DSA were in agreement in grading of grade 1 stenosis in right segmental artery and left proximal renal artery (white arrows). The collateral branches formed secondary to the stenosis in inferior mesenteric artery origin are well demonstrated by CE-MRA.

\section{DSA Findings}

Of 25 patients, 50 main and 13 accessory arteries were visualized by DSA. In these arteries; 9 grade 1, 1 grade 2, 5 grade 3 (15 in total) stenosis were depicted. Of these stenoses, 11 were in proximal segment, 2 were in segmental artery, and 2 were in accessory artery. One patient had a dissecting abdominal aortic aneurysm extending to both common iliac arteries. In another patient; abdominal aorta, the origin of inferior mesenteric artery, and both common iliac arteries were severely narrowed by multiple large atheroma plaques.

\section{FISP Sequence Findings}

Of 5 kidneys with hemodynamically significant RAS, mean craniocaudal dimension was $9.38 \mathrm{~cm}$. Mean craniocaudal dimension of contralateral kidneys of the same patients was $10.52 \mathrm{~cm}$. Of the kidneys with RAS, mean parenchymal thickness was $1.36 \mathrm{~cm}$ whereas mean parenchymal thickness of the contralateral kidneys without stenosis was $1.82 \mathrm{~cm}$. The differences in craniocaudal dimensions and parenchymal thicknesses between kidneys with and without RAS were not statistically significant $(p<0.05)$. Of the study population, 1 had unilateral multiple parapelvic cysts, 1 had unilateral hydroureteronephrosis, 1 had parenchymal and calyceal structural alterations due to chronic pyelonephritis. A $6 \times 3 \mathrm{~cm}$ surrenal mass which was probably a pheochromacytoma and multiple hyperintense lesions which were probably hamartomas were depicted in a patient who was under the follow-up for neurofibromatosis.

\section{CE-MRA Findings}

CE-MRA demonstrated all 50 main and 11 of 13 accessory renal arteries. Of 50 main renal arteries, 29 were in group 1, and 21 were in group 2 . Of 21 invisible segmental arteries, the reason of fail in demonstrating segmental arteries were as followings: respiratory artifacts in 4 subjects, overdelay of acquisition following contrast injection in 7 subjects, and splenic artery superposition in 1 subject.

Nine proximal renal, 1 segmental, and 2 accessory renal (12 in total) arterial stenoses were depicted. Of these 12 stenosis; 5 were grade 1, 2 were grade 2, 5 were grade 3 . Table 1 provides comparative results of DSA and CE-MRA in grading stenosis. For 5 of 9 stenoses defined as grade 1, CEMRA was in agreement with DSA (Figure 1). Three of 9 grade 1 stenosis was not depicted by CE-MRA; 2 of these were at proximal segment and 1 was at segmental artery. One grade 1 stenosis was defined as grade 2 by CE-MRA. In 1 grade 2 and 5 grade 3 stenoses, DSA and CE-MRA gradings were the same. In a patient who was a candidate for PTRA, a grade 1 proximal segment stenosis and grade 2 accessory arterial stenosis were depicted, in agreement with DSA (Figure 2). In post-PTRA DSA images, there was no change in proximal renal arterial stenosis, but the one in the accessory artery 


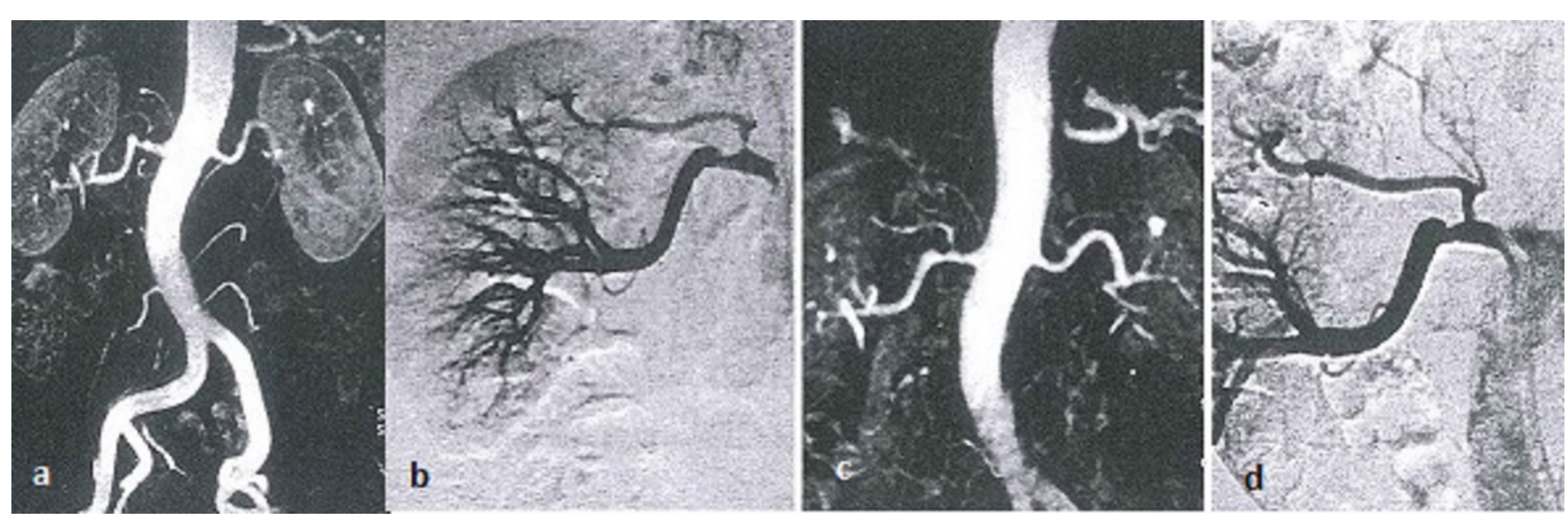

Figure 2. a) Pre-PTA CE-MRA b) Pre-PTA DSA c) Post-PTRA CE-MRA d) Post-PTRA DSA. CE-MRA depicted a grade 1 and a grade 3 stenosis in the right renal artery and right accessory artery, in this canditate for PTRA; gradings were in agreement with DSA. Post-PTRA CE-MRA showed persistance of the stenosis in accessory artery where the post-PTRA DSA showed a normalized lumen calibration. This may be attributed to CE-MRA being performed one day after DSA performance, or may be the result of ongoing flow-pattern abnormality although the stenosis was completely removed.

was completely vanished. However, by CE-MRA, no difference in either stenosis was found in post-PTRA images compared to pre-PTRA images. The sensitivity, specificity, positive and negative predictive values of CE-MRA in diagnosing RAS were; $100 \%, 97.8 \%, 87.5 \%$, and $100 \%$, respectively.

One patient had a dissecting abdominal aortic aneurysm extending to both common iliac arteries. In another patient; abdominal aorta, origin of the inferior mesenteric artery, and both common iliac arteries were narrowed by multiple large atheroma plaques. The stenosis at the abdominal aorta and common iliac arteries were better diagnosed by MIP images, but the stenosis in the origin of inferior mesenteric artery was more obvious in native images.

\section{DISCUSSION}

RAS constitutes the most common cause of secondary hypertension, with an approximate prevalence of $5 \%$. It can be the result of atherosclerotic disease or fibromuscular dysplasia. Early diagnosis and treatment of RAS is essential to prevent loss of renal function and other systemic effects of hypertension [7]. The choice of the ideal imaging method for the assessment of patients suspected of having RAS remains questionable. DUS is a noninvasive and a widely available imaging method [8]. However, it is an operatordependent technique and imaging may be limited by obesity and gas superposition. Another limitation of the method is, renal arterial anatomical variations and distal reconstitution by collateral vessels may cause false negative results. For these reasons, combined use of DUS with another imaging method that visualizes anatomical details of renal arteries may be needed.
Contrast enhanced CTA (CE-CTA) and CE-MRA are other techniques for the demonstration of renal vasculature. Diagnostic performances of these techniques are reported to be satisfactory $[9,10]$. Currently, cross-sectional imaging methods are being preferred as first line diagnostic tools to assess both arterial and venous system of the kidneys and DSA has been reserved only for therapeutic intervention, in many centers. CE-CTA and CE-MRA demonstrate not only the lumen of the vessel as in DSA, but also provide images of the vessel wall, renal parenchyma, collecting system, and neighboring soft tissues [2]. However, CE-CTA requires iodinated contrast media, and involves radiation [11]. CEMRA present high diagnostic performance in the assessment of the renal arteries and its sensitivities and specificities in the evaluation of RAS are reported to be upward of $90 \%$ [2]. In agreement with the previous data, we found sensitivity and specificity of CE-MRA to be $100 \%$ and $97.8 \%$, respectively. Besides high diagnostic performance in depicting renal arteries, CE-MRA reliably demonstrated accessory renal arteries. Adding FISP sequence in coronal and axial planes, we were able to obtain the images of renal parenchymal and pelvicalyceal structural alterations, and mass lesions of the kidney and the surrenal gland.

Gadolinium-based contrast agents (GBCA) show low rates of development of nephrotoxicity [12-13] and allergic complications [14] compared with those rates for iodinated contrast materials. The administration of gadolinium with MRI provides contrast enhancement to be evaluated without exposure to ionizing radiation. Until recently, these agents were used at high doses in patients with renal failure. However, in 2006, an association between GBCA and nephrogenic systemic fibrosis (NSF) has been recognized. This observation changed the way that gadolinium is used 
[15], and non-contrast-enhanced MRA techniques, including time of flight, phase contrast, and balanced steady state free precession imaging, have been studied to assess the degree of stenosis [7, 16-19]. According to the guidelines of administration of contrast agents, the risk of post-contrast acute kidney injury is very low when gadolinium-based contrast agents are used in approved doses. Reduced renal function, particularly if GFR $<15 \mathrm{ml} / \mathrm{min} / 1.73 \mathrm{~m}^{2}$, is defined as a risk of development of NSF. Based on laboratory data, linear GBCA are defined to entertain the highest risk of NSF, and the cyclic GBCA are recommended in patients with $\mathrm{GFR}<15 \mathrm{ml} / \mathrm{min} / 1.73 \mathrm{~m}^{2}$ [20]. Of none of the patients in our study population, GFR were $<15 \mathrm{ml} / \mathrm{min} / 1.73 \mathrm{~m}^{2}$.

In conclusion; we offer 3D CE-MRA technique in not only detecting RAS, but in demonstrating accessory arteries as well.

\section{DECLARATION OF CONFLICT OF INTEREST}

The author declared no conflicts of interest with respect to the authorship and/or publication of this article.

\section{REFERENCES}

1. Samadian F, Dalili N, Jamalian A. New insights into pathophysiology, diagnosis, and treatment of renovascular hypertension. Iranian J Kidney Dis 2017; 11: 79-89.

2. Vasbinder GB, Nelemans PJ, Kessels AG, et al. Diagnostic tests for renal artery stenosis in patients suspected of having renovascular hypertension: a meta-analysis. Ann Intern Med 2001; 135: 401-11.

3. Granata A, Fiorini F, Andrulli S, et al. Doppler ultrasound and renal artery stenosis: An overview. J Ultrasound 2009; 12: 133-43.

4. Turgutalp K, Kiykim A, Özhan O, Helvaci I, Ozcan T, Yıldız A. Comparison of diagnostic accuracy of Doppler USG and contrast-enhanced magnetic resonance angiography and selective renal arteriography in patients with atherosclerotic renal artery stenosis. Med Sci Monit 2013; 19: 475-82.

5. Lenz T, Schulte KL. Current management of renal artery stenosis. Panminerva Med 2016; 58: 94-101.

6. Tuna IS, Tatlı S. Contrast-enhanced CT and MR imaging of renal vessels. Abdom Imaging 2014; 39: 875-91.

7. Miyazaki $M$, Isoda $H$. Non-contrast-enhanced $M R$ angiography of the abdomen. Eur J Radiol 2011; 80: 9-23.
8. Radermacher J, Chavan A, Bleck J, et al. Use of Doppler ultrasonography to predict the outcome of therapy for renal artery stenosis. N Eng J Med 2001; 344: 410-7.

9. Olbricht CJ, Paul K, Prokop M, et al. Minimally invasive diagnosis of renal artery stenosis by spiral computed tomography angiography. Kidney Int 1995; 48: 1332-7.

10. Grovic VD, Achaumer MA, Kittner T, et al. Gadodiamideenhanced $M R$ angiography to intraarterial digital subtraction angiography for evaluation of renal artery stenosis: results of a phase III multicenter trial. J Magn Reson Imaging 2010; 31: 390-7.

11. Miyazaki M, Akahane M. Non-contrast enhanced MR angiography: Established techniques. J Magn Reson Imaging 2012; 35: 1-19.

12. Prince MR, Arnoldus C, Frisoli JK. Nephrotoxicity of highdose gadolinium compared with iodinated contrast. J Magn Reson Imaging 1996; 6: 162-6.

13. Rofsky NM, Weinreb JC, Bosniak MA, Libes RB, Birnbaum BA. Renal lesion characterization with gadoliniumenhanced MR imaging: efficacy and safety in patients with renal insuficiency. Radiology 1991; 180: 85-9.

14. Murphy KJ, Brunberg JA, Cohan RH. Adverse reactions to gadolinium contrast media: a review of 36 cases. AJR Am J Roentgenol 1996: 167: 847-49.

15. Prince MR, Zhang HL, Prowda JC, et al. Nephrogenic systemic fibrosis and its impact on abdominal imaging. Radiographics 2009:29:1565-74.

16. Yamuna J, Chandrasekharan A, Rangasami R, Ramalakshmi S, Joseph S. Unenhanced renal magnetic resonance angiography in patients with chronic kidney disease \& suspected renovascular hypertension: Can it affect patient management? Indian J Med Res 2017; 146: 22-9.

17. Gondalia R, Vernuccio F, Marin D, Bashir MR. The role of $M R$ imaging in the assessment of renal allograft vasculature. Abdom Radiol (NY) 2018 Apr 26. (doi: 10.1007/s00261-018-1611-3).

18. Laader A, Beiderwellen K, Kraff O, Maderwald S, Ladd ME, Forsting M, Umutlu L. Non-enhanced versus low-dose contrast-enhanced renal magnetic resonance angiography at $7 \mathrm{~T}$ : a feasibility study. Acta Radiol. 2018 Mar; 59(3): 296-304. 
19. Liang KW, Chen JW, Huang HH, Su CH, Tyan YS, Tsao TF. The Performance of Noncontrast Magnetic Resonance Angiography in Detecting Renal Artery Stenosis as Compared With Contrast Enhanced Magnetic Resonance Angiography Using Conventional Angiography as a Reference. J Comput Assist Tomogr. 2017 Jul/Aug; 41(4): 619-627.
20. ESUR Guidlines on Contrast Media v 10.0. (last updated: 09:33 Mon 26 Mar 2018). Available from: http://www.esur.org/esur-guidelines/ 